\title{
Teachers Dietary Practices during School Day in Jeddah, Western Saudi Arabia
}

\author{
Balkees Abed Bakhotmah \\ Department of Nutrition \& Food Sciences, The Art and Design College, King Abdulaziz University, Jeddah, Saudi Arabia. \\ Email: hbaab1961@yahoo.com
}

Received September $27^{\text {th }}$, 2012; revised October $27^{\text {th }}$, 2012; accepted November $5^{\text {th }}, 2012$

\begin{abstract}
The schools teachers dietary practices during the school day should reflect a healthy dietary pattern both in quality and quantity of foods consumed particularly in countries that witness an epidemic of obesity related Type- 2 diabetes mellitus. The objective of this study was to identify the local dietary practices of the schools teachers in Jeddah, western Saudi Arabia. A Cross-section observational study using a pre-designed questionnaire to identify the local pattern of dietary practices during school day of a representative sample of schools teachers was conducted in Jeddah. The questionnaire was piloted and administered to a sample of 140 teachers working in 15 schools across Jeddah. A total of 140 Saudi teachers participated. The mean age of the sample was $34.9 \pm 6.1$ years. Two thirds (66.4\%) were females. Overall, $40.5 \%$ were overweight and $22.4 \%$ were obese. During the school day, tea and Arabic coffee were the commonest daily consumed drinks (67.9\%, 65.7\% respectively). Almost half of the sample consumed dates on a daily basis (51.4\%). Breads and cheese sandwiches were always consumed by $45 \%$ and $33.6 \%$ respectively. Two thirds of females $67.7 \%$ and 55.3\% of males were used to have breakfast and/or snack with their colleagues at school. Males preferred to purchase ready-made traditional foods from outside while females preferred the schools canteens. The percentages of overweight and obesity were higher among males compared to females (46.5\% versus $37 \%)$ and (25.6\% versus $20.5 \%)$ respecttively. It is concluded that the dietary practices of Saudi school teachers during school day vary according to gender. Findings indicate the need for dietary modification programs directed towards schools teachers in populations which report high prevalence rates of diabetes of similar cultural backgrounds.
\end{abstract}

Keywords: Foods; Dietary Practices; Nutritional Behavior; Schools

\section{Introduction}

In the eyes' of their students, the schools teachers are role models who "practice what they preach" [1]. In addition to the positive role modeling, school teachers can affect students' eating habits in other ways including through nutrition knowledge and avoidance of unhealthy classroom food practices [2,3]. The teachers' nutritional behavior, dietary practices and eating habits at the school are usually well observed by students. On the long term, teachers' foods practices and nutritional behaviors during school day including their dietary pattern both in quality and quantity of foods consumed may transmit to their students [2]. Food practices during the school day vary between nations and sometimes in the same nation depending on cultural, socio-economic and educational backgrounds [1-3]. The identification of these food practices during the school day may help in designing future educational nutritional programs that support healthy food practices in the schools' environment particularly in countries that witness an epidemic of obesity related
Type-2 diabetes mellitus.

Saudi Arabia and other adjacent gulf countries are witnessing rapidly increasing rates of Type 2 Diabetes Mellitus, a chronic debilitating medical condition strongly related to obesity. At least one out of five Saudis (i.e. more than three million individuals) are diabetic in Saudi Arabia [4]. The rates of overweight or obesity are similarly increasing, particularly in females which approached $65.4 \%$ in the eastern region and $70.5 \%$ in the western region of Saudi Arabia [5,6]. Lower rates of 43.35\% were reported among Saudi males [7].

The changes in prevalence rates of overweight, obesity and other related chronic metabolic diseases, particularly diabetes, were attributed to the major socio-cultural and lifestyle changes which accompanied an overall increase of per capita income and recent modernization of Middle Eastern oil countries [5,8], the promotion of unhealthy fast foods [9], the recent changes in Saudi diet both in quantity and quality $[9,10]$ and increasing rates of physical inactivity which reached rates ranging between $43.3 \%$ - 99.5\% [11]. 
A previous study on Jeddah's population indicated that the consumption of both "traditional" and westernized "junk" foods was the highest in the nation and averaged 1 - 3 times per week in $64.3 \%$ of a studied population of 1067 adolescent female school students [12]. In another study conducted on adolescent Saudi girls living in Jeddah, $56.6 \%, 30.5 \%$ and $13.0 \%$ of their energy intake was derived from carbohydrates, fats, and proteins, respecttively [13]. The resultant dietary and behavioral shifts affected both sexes and all age groups particularly the younger generations who are potential victims for obesity-related Type 2 diabetes mellitus in Saudi Arabia and adjacent gulf countries [14].

The school teachers are expected to play a major role in the war on the obesity-related type 2 diabetes mellitus through adopting healthier food practices while at schools and in their communities. To achieve this goal their knowledge, attitudes, and food behaviors during the school day should promote healthy dietary pattern and eating habits.

This study was conducted on a convenience sample of Saudi teachers working in a sample of randomly selected schools in Jeddah, the second largest cosmopolitan city in Saudi Arabia. It aimed to identify the local dietary practices of the schools teachers during the school day. The identification of these food practices will hopefully help in designing future educational nutritional programs and developing policies and regulations in schools that target schools teachers in Saudi Arabia and perhaps similar gulf countries.

\section{Methods}

This is a cross sectional observational study which was performed on a convenience sample of Saudi schools teachers in Jeddah. It was hypothesized that teachers are educated and influential group in developing countries. Teachers school- day's dietary practices may reflect their nutritional awareness not only in school but also in daily life. Identification of the local dietary practices may help in outlining future nutritional educational programs to this influential group in all communities and particularly countries which witness high prevalence rates of obesity related Type- 2 diabetes mellitus such as Saudi Arabia and adjacent Gulf States.

The sample of the current study was a convenient sample that enrolled teachers from a sample of randomly selected schools across Jeddah city. The author (B.B.) was a senior teacher, worked in the Schools Health Services Clinic and had observed the teachers practices during her work in the schools sector. To achieve the study objectives, the official registry of all Jeddah's public schools was obtained from the Directorate of Education Office, Ministry of Education. In that registry, the total numbers of public schools were distributed on 5 sectors according to their geographical location in Greater Jeddah city. Three schools (one males and two females schools) from each sector were selected randomly from each sector $(n=15)$. A convenient sample of at least 10 females' teachers per school in 10 female public schools and 5 males per school in 10 males' public schools were invited to voluntarily participate in filling answers to a pre-designed self-administered questionnaire and self-report their height in meters and weight in kilograms. The body mass index BMI was calculated by the author. One hundred female teachers in 10 public females' schools and fifty males were invited in 5 public schools were invited to participate. The response rate was comparable in the two groups as 93/100 female teachers accepted to participate compared to $47 / 50$ in the male group. One hundred forty teachers completed the questionnaire. Out of the 140 teachers, 116 self-reported their height and weight $(82.8 \%)$.

The self-administered questionnaire used in this study was developed by the author based on her previous observations as a senior teacher and knowledge of local culture. It aimed to identify the teachers' dietary practices including dietary habits and nutritional behavior during the school day and correlate some of these practices to the teachers' BMI. The preliminary pre-designed questionnaire was peered reviewed by two reviewers and piloted on nutrition students by the author (BB).

The questionnaire consisted of eight sections: 1 ) The socio-demographic data of the participating teachers which included age, gender, marital status; 2) History of chronic illnesses including diabetes mellitus; 3) Preferable timing and place of taking breakfast: home or school; and if in school whether it is taken alone or with colleagues "eating in large group"; 4) Sources of foods and drinks consumed during school day: home, schools canteen or shops/ restaurants around the school; 5) The top five foods items including solid foods and drinks which are preferably consumed on daily basis during school day i.e. foods which participants considered as "must have daily"; 6) Frequency of solid foods consumption which are preferably consumed during school day as breakfast and/or snack over the week days; 7) Frequency of drinks consumption which are preferably consumed during school day with breakfast and/or snack over the week days; 8) The last section was about self-reported weight in kilograms and height in meters.

For the purpose of study, normal BMI of teachers was defined as BMI of 20 - 24.9, overweight as BMI of 25 29.9 and obese when BMI was 30 and above. The teachers' food practices during school day were defined as any food consumption during the school day which usually starts at 7 am and terminates between 12 noon and 2 pm including late breakfast and snacks. For the sake of analysis the solid foods and drinks consumed over the 
week days were arranged in the frequency tables according to this sequence of frequency: "Always", "Twice weekly", "Once weekly" and "Sometimes”. The items which were always taken are top on the list and "always" refers to three or four times per week but not daily. Breakfast at home refers to having breakfast within 30 minutes of waking up at home and before leaving to school. "Eating in large group" at school refers to dining with more than 5 colleagues in the school during breaks whether it is breakfast meal and/or additional snacks taken during the school day.

The data was entered and processed using SPSS ver 16 program. Data analysis was performed by using the same statistical software package. The descriptive statistics was presented in the form of frequencies and percentages for qualitative variables. Qualitative variables were compared using chi-square test, whenever the expected count is less than five in more than $20 \%$ the cells or the expected count in a cell is less than one in large tables (more than $2 \times 2$ ), the test was not applicable and its contents were presented in cross tabulated form. Student $t$ test was used to compare independent two normally distributed subgroups. $\mathrm{P}$ value less than 0.05 was considered significant throughout the study.

\section{Results}

A total of 150 (100 female +50 males) teachers were invited to participate. One hundred forty teachers (93.3\%) completed the questionnaire and the response rate was almost comparable in the two groups as 93/100 female teachers accepted to participate compared to $47 / 50$ in the male group. Out of the 140 teachers, 116 self-reported their height and weight (82.8\%). The mean age of the sample was $34.9 \pm 6.1$ years. Two thirds (66.4\%) were females, and almost three quarters (72.9\%) were married Table 1.

Table 1. Socio-demographic characteristics of the study group $(n=140)$.

\begin{tabular}{ccc}
\hline Characteristics & No. & $\%$ \\
\hline Age (years) & 16.9 & 16.9 \\
$<30$ years & 57.6 & 57.7 \\
$30-<40$ years & 25.4 & 25.4 \\
$40+$ years & $34.9 \pm 6.1$ years \\
Mean \pm SD & & \\
Gender & 47 & 33.6 \\
Male & 93 & 66.4 \\
Female & & \\
Marital status & 102 & 72.9 \\
Married & 38 & 27.1 \\
Single & & \\
\hline
\end{tabular}

The mean estimated $\mathrm{BMI} \pm \mathrm{SD}$ for the studied sample was $26.8 \pm 5.5$. More than one third of the studied teachers $(37.1 \%)$ reported normal BMI, and the remaining were either overweight (40.5\%) or obese (22.4\%). BMI was slightly higher among males (mean $\pm \mathrm{SD}, 27.8 \pm 6.6$ ) than females (mean \pm SD, $26.3 \pm 4.7$ ) without statistical significance $\mathrm{p}>0.05$, Table 2 .

Diabetes mellitus and lower limbs varicosities were reported by $(4.3 \%)$ of the participants and came as second on the list of chronic illnesses after hypertension which was reported by (5.7\%). Almost one third of the male teachers (36.2\%) and one quarter of the females (25.8\%) indicated that they were always taking their breakfast early before leaving to school compared to $38.3 \%$ and $37.6 \%$ respectively who rarely had breakfast at home, however this difference was not statistically significant, Table 3. More than one half of the males (55.3\%) and two thirds of the females (67.7\%) reported "Eating in large group" i.e. taking breakfast and/or snacking with their colleagues at the schools during their breaks time. However, there were no statistically signifycant differences among the teachers according to their gender $\mathrm{p}>0.05$ in that regard, Table 3 .

Regarding the sources from which the teachers were getting their foods for breakfast and/or snacking during schools day, females preferred to purchase food and drinks from the schools canteens more than males as $11.8 \%$ of the female teachers were always purchasing their breakfast from the schools canteen compared to none among males. Moreover, it was remarked that $35.5 \%$ of the female teachers addressed that they were sometimes buying their food for breakfast and/or snacks from canteen compared to $19.1 \%$ of males, and these preferences patterns were statistically significant $\mathrm{p}<0.05$. In contrast, it was found that the percentage of male teachers who were always getting their food from the shops/restaurants outside the school (63.8\%) was significantly higher than that among the female teachers (28\%) $\mathrm{p}<0.05$. The differences between males and females teachers was not as significant when it comes to bringing foods/drinks with them to schools for breakfast and/or snaking Table 3.

Table 2. Body Mass Index BMI of the teachers according to gender.

\begin{tabular}{|c|c|c|c|c|c|c|}
\hline \multirow{3}{*}{ Characteristics } & \multicolumn{4}{|c|}{ Gender } & \multirow{3}{*}{$X^{2}$} & \multirow{3}{*}{$\mathrm{p}$ value } \\
\hline & \multicolumn{2}{|c|}{ Males } & \multicolumn{2}{|c|}{ Females } & & \\
\hline & No. & $\%$ & No. & $\%$ & & \\
\hline Normal & 12 & $27.9 \%$ & 31 & $42.5 \%$ & & \\
\hline Overweight & 20 & $46.5 \%$ & 27 & $37.0 \%$ & 2.459 & 0.292 \\
\hline Obese & 11 & $25.6 \%$ & 15 & $20.5 \%$ & & \\
\hline
\end{tabular}


Table 3. Dietary practices among teachers according to their gender.

\begin{tabular}{|c|c|c|c|c|c|c|}
\hline \multirow{3}{*}{ Dietary Practices } & \multicolumn{4}{|c|}{ Gender } & \multirow{3}{*}{$X^{2}$} & \multirow{3}{*}{$\mathrm{p}$ value } \\
\hline & \multicolumn{2}{|c|}{ Males } & \multicolumn{2}{|c|}{ Females } & & \\
\hline & No. & $\%$ & No. & $\%$ & & \\
\hline \multicolumn{7}{|l|}{ Early breakfast at home } \\
\hline Always & 17 & $36.2 \%$ & 24 & $25.8 \%$ & & \\
\hline Sometimes & 12 & $25.5 \%$ & 34 & $36.6 \%$ & 2.304 & 0.316 \\
\hline Rarely & 18 & $38.3 \%$ & 35 & $37.6 \%$ & & \\
\hline \multicolumn{7}{|c|}{ Breakfast and/or snacking at school } \\
\hline Alone & 10 & $21.3 \%$ & 16 & $17.2 \%$ & & \\
\hline Eating with colleagues & 26 & $55.3 \%$ & 63 & $67.7 \%$ & & \\
\hline \multicolumn{7}{|c|}{ Sources of breakfast and/or snack From canteen } \\
\hline Always & 0 & $.0 \%$ & 11 & $11.8 \%$ & & \\
\hline Sometimes & 9 & $19.1 \%$ & 33 & $35.5 \%$ & 12.321 & 0.002 \\
\hline No & 38 & $80.9 \%$ & 49 & $52.7 \%$ & & \\
\hline \multicolumn{7}{|l|}{ From outside school } \\
\hline Always & 30 & $63.8 \%$ & 26 & $28.0 \%$ & & \\
\hline Sometimes & 10 & $21.3 \%$ & 31 & $33.3 \%$ & 17.360 & $<0.000$ \\
\hline No & 7 & $14.9 \%$ & 36 & $38.7 \%$ & & \\
\hline \multicolumn{7}{|l|}{ From home } \\
\hline Always & 6 & $12.8 \%$ & 22 & $23.7 \%$ & & \\
\hline Sometimes & 14 & $29.8 \%$ & 22 & $23.7 \%$ & 2.438 & 0.296 \\
\hline No & 27 & $57.4 \%$ & 49 & $52.7 \%$ & & \\
\hline
\end{tabular}

Tea was the most preferred consumed food/drink item which was consumed on a daily basis i.e. "must have daily" by teachers during school day and been reported as the most common preferably consumed drink by (67.9\%) of respondents followed by Arabic coffee (65.7\%). The least daily consumed drink by the studied teachers at the school day was other types of instant coffee $(23.6 \%)$. Meanwhile, it was noted that the most commonly preferably consumed foods were dates as almost one half of the teachers were preferably eating it on daily basis while at school (51.4\%).

However, when it comes to the frequency of other foods and drinks taken by teachers in the school over the week days, it was found that the traditional bread called locally "Tamees" was always taken by $45.0 \%$ of teachers during their eating in group at schools. Tamees is commonly dipped in tea or in a common traditionally cooked and mashed fava beans dish called locally "Ful" in $7.1 \%$ of the sample. The second favorite food which was always taken by $33.6 \%$ of respondents was plain cheese sandwiches. Similarly, it was noticed that the commonest drinks which were always consumed by teachers were milk in $24.3 \%$ followed by canned juices in $21.4 \%$, Table 4.

\section{Discussion}

The current study is a cross-sectional study on a convenience sample of Saudi teachers in Jeddah, Saudi Arabia which aims to explore the dietary pattern, foods practices and eating habits of a representative sample of relatively young teachers during the school day. Identification of these practices and of foods preferably consumed by teachers showed some interesting differences when compared to similar few studies in the literature [1-3]. All of the previously mentioned studies were conducted in North American schools and involved selected sample of teachers: teachers teaching nutrition in Oregon, USA [1], future teachers in Ontario, Canada [2]; and middle school teachers in Minnesota USA [3]. The current study is perhaps the first published from Saudi Arabia on school teachers and unlike previous studies it explored the attitudes of teachers teaching all subjects.

The importance of teachers' role in adopting healthy food practices during the school day and in classrooms which will hopefully be followed by schools students who usually consider their teachers as role models was already stressed [13]. This role is as important if not more in a country like Saudi Arabia that witnessed a 
Table 4. Frequency of taking common foods and drinks taken during the school day as breakfast/snack.

\begin{tabular}{|c|c|c|c|c|c|c|c|c|}
\hline \multirow{3}{*}{ Food items } & \multicolumn{8}{|c|}{ Frequency } \\
\hline & \multicolumn{2}{|c|}{ Always } & \multicolumn{2}{|c|}{ Twice weekly } & \multicolumn{2}{|c|}{ Once weekly } & \multicolumn{2}{|c|}{ Sometimes } \\
\hline & No. & $\%$ & No. & $\%$ & No. & $\%$ & No. & $\%$ \\
\hline \multicolumn{9}{|l|}{ Solid food } \\
\hline Breads (tamees) & 63 & $45.0 \%$ & 6 & $4.3 \%$ & 1 & $0.7 \%$ & 3 & $2.1 \%$ \\
\hline Cheese sandwich & 47 & $33.6 \%$ & 21 & $15.0 \%$ & 12 & $8.6 \%$ & 25 & $17.9 \%$ \\
\hline Egg sandwich & 13 & $9.3 \%$ & 11 & $7.9 \%$ & 14 & $10.0 \%$ & 24 & $17.1 \%$ \\
\hline Beans (ful) & 11 & $7.9 \%$ & 5 & $3.6 \%$ & 3 & $2.1 \%$ & 18 & $12.9 \%$ \\
\hline Rusk (shabora) & 10 & $7.1 \%$ & 13 & $9.3 \%$ & 6 & $4.3 \%$ & 27 & $19.3 \%$ \\
\hline Falafel (tamiah) & 4 & $2.9 \%$ & 7 & $5.0 \%$ & 11 & $7.9 \%$ & 33 & $23.6 \%$ \\
\hline Fast foods & - & - & 1 & $0.7 \%$ & 9 & $6.5 \%$ & 33 & $23.6 \%$ \\
\hline \multicolumn{9}{|l|}{ Drinks } \\
\hline Milk & 34 & $24.3 \%$ & 9 & $6.4 \%$ & 6 & $4.3 \%$ & 17 & $12.1 \%$ \\
\hline Canned juices & 30 & $21.4 \%$ & 4 & $2.9 \%$ & 9 & $6.4 \%$ & 20 & $14.3 \%$ \\
\hline Aerated drinks & 16 & $11.4 \%$ & 7 & $5.0 \%$ & 7 & $5.0 \%$ & 16 & $11.4 \%$ \\
\hline Fresh juice & 8 & $5.7 \%$ & 9 & $6.4 \%$ & 11 & $7.9 \%$ & 22 & $15.7 \%$ \\
\hline Yogurt & 8 & $5.7 \%$ & 5 & $3.6 \%$ & 4 & $2.9 \%$ & 18 & $12.9 \%$ \\
\hline
\end{tabular}

paradigm shift in life-style and nutritional behavior [8, 11]. Such a positive role modeling among school teachers may be pivotal in reducing the increasing rates of overweight/obesity in youngsters $[4,10,14]$ and prevention of the obesity-related type 2 diabetes mellitus $[4,10]$ which is the most common chronic debilitating illness affecting the Gulf States citizens [4]. The schools are in the center of this obesity epidemic and should be an educational venue for good nutritional practices for both students and teachers.

The prevalence of self-reported diabetes mellitus in the studied sample is $4.3 \%$ which is much less than that reported in the literature of almost $20 \%$ in Saudis [4]. This can be explained on the basis of the relatively young mean age of the participants (34.9 years), the mean BMI of 26.8 and predominance of normal weight females in the studied sample. Overall, $40.5 \%$ of the studied teachers were overweight and $37.1 \%$ were obese and the BMI in males were insignificantly higher than females which may be explained again on the tendency of females on watching their weight at this age. These findings may indicate the timely need for preventive measures against obesity and subsequently related diabetes mellitus at this early age.

A significant percentage of studied teachers skipped breakfast at home before coming to school particularly females $74.2 \%$ who reported that they sometimes or rarely had breakfast at home. It is not therefore surprising that $76.6 \%$ of males and $84.9 \%$ of females reported regular eating of breakfast and/or snacking in schools,
Table 3. The females were more towards having foods with their colleagues compared to males in a phenomenon called "Eating in large group" when several teachers gather during breaks and share foods. This practice was already correlated to increasing food consumption [15].

It was also reported that the males' teachers were more likely to purchase foods items from outside the schools and rarely purchasing it from the school store or canteen. The opposite trend was reported by the females who were more towards having the foods items available in the school canteen. This variation in the sources of food items consumed in school between the two genders was statistically significant. This pattern was attributed to the local schools policies which prevent females from getting outside school during the school day and lack of transportation to get around unlike males who have these advantages. These logistics in purchasing food items may complicate the issue of providing healthy foods as the males' teachers have direct access to all kinds of healthy and unhealthy food items. In contrast, this unintended setup of females' schools may facilitate the implementation of future policies and regulations by improving the selection process and limiting the foods items offered in the schools' environment to the healthy ones.

When it comes to the foods items consumed by teachers on a daily basis, $67.9 \%$ of the studied teachers put tea on the top of the list of preferred foods which, followed by Arabic coffee in $65.7 \%$ and finally dates in $51.4 \%$. These three items for them were considered as the daily favorites. Hakim et al. in a national study on coronary 
heart disease (CHD) on 3430 Saudi subjects reported a high daily consumption of black tea among the studied sample which amounted to $91.8 \%$ of men and $87.2 \%$ of women [16]. The mean daily consumption was 5.6 cups and 3.4 cups in men and women respectively [16]. Therefore, selection of tea as the most favored food item is not a surprise in the current study. This trend should be encouraged as it is a low-calories drink which is already positively correlated to lesser rates of high blood pressure and CHD [16]. The second favorite drink was the un-sweetened Arabic coffee which is again a low-calories hot drink. It is made of green Coffea arabica Linn. beans and commonly consumed by Saudis associated with dates. Data on its effect on lowering blood pressure [17] and raising the serum cholesterol levels $[18,19]$ were already published. However, controversies about potential risks and benefits still exist [20]. Overall, both tea and coffee are low-calories drinks when ingested in moderate amounts. Dates were the third favorite food item as half of the participants in the current study were keen to have it on daily basis. Dates (Phoenix dactylifera L.) are the fruits of palm trees which were described in the literature as a functional medicinal food [21-23]. Dates are low GI diet and not similar to candies if consumed with moderation [22]. In view of that dates consumption should be encouraged in the Saudi's schools as an ideal fruit with several nutritional and functional properties irrespective of its variety [23]. Dates were the only fruit which was consumed on daily basis in our sample and none of the participants reported regular vegetables consumption in this sample. This pattern indicates the need of more education on the importance of having more fruits and vegetables by teachers at schools.

The other foods items which were liked and consumed by teachers in high frequency at school during the school days were: the traditional bread called locally "Tamees" which is made of flour into a large piece of fast baked flat circular bread and was always taken by $45.0 \%$ of teachers during their eating in large group at schools. "Tamees" is commonly dipped in tea or in a common traditional cooked and mashed fava beans (legume) curry dish called locally "Ful" in $7.1 \%$ of the sample. "Tamees" and "Ful" is truly traditional Saudi favorite which is taken commonly at breakfast and at dinner times. Both are bought as a ready-meal for consumption meal. Its price is affordable and it has high protein content driven from "Ful" and high carbohydrate from "Tamees'. This wheat bread (355 g/head/day) provided 45 and 61\% of energy and protein requirements respectively at national level per person per day $[24,25]$. Nutritional evaluation of some legume-based dishes consumed in Saudi Arabia was already studied by al-Kanhal et al. who indicated that legume-based dishes which include "Ful" contributed to $13 \%-25 \%, 15 \%-64 \%$ and $16 \%-60 \%$ of the total food energy from protein, fat and carbohydrates respectively. They concluded that most of these dishes were good sources of dietary fiber, vitamin A and iron [26]. However, it must be taken with moderation similar to any other food items as the association between ready-meal consumption and overweight has already been reported [27]. The sharing of this meal and eating it in large group may increase its consumption significantly.

It was also noticed that the commonest drinks which were always consumed by teachers were milk in $24.3 \%$ followed by canned juices in $21.4 \%$. Milk consumption should be encouraged in view of the high osteoporosis rates among Saudis which were reported recently [28]. The consumption of sweetened drinks is perhaps low when compared to similar studies in United States where prevalent use of vending was a particular concern, with beverage and snack vending use reported by $62 \%$ and $35 \%$ of teachers, respectively. Most vending items purchased were sweetened drinks (57\%) and high-fat or high-sugar snacks (85\%) [3].

The current study has few limitations which include the relatively small size of the studied sample and the data was based on teachers' self-reported behaviors and may not represent their actual practices. Some of the teachers may have had difficulty understanding some of the survey questions and some of the survey directions. However, it served its aim on shedding light of some of the common foods practices of teachers while at schools and further research is needed on the common ones.

In conclusion, the schools are a key venue for health promotion and obesity prevention. The available findings suggest that some practices, eating habits and food behaviors of our teachers may be barriers to promoting healthy food habits in schools environment. The good practices should be encouraged and supported while the unhealthy one need review and tuning by policies and regulations that support healthy nutritional foods practices at schools. Teachers should be involved in the schools policy development to promote awareness and implementation among them. The habit of eating in large groups should be discouraged. In the meantime, foods brought to schools by teachers and those offered in canteen for students/teachers should include more healthier foods particularly fruits and vegetables. The high calories foods items should be controlled in school environment. Further wide scales studies on teachers are timely needed to improve the current practices of teachers during school day.

\section{Acknowledgements}

The author acknowledges Prof. H. Alzahrani for reviewing the manuscript and Dr A. Ibrahim for statistical assistance. 


\section{REFERENCES}

[1] J. D. Skinner and M. J. Woodburn, "Dietary Practices of High School Teachers of Nutrition," Journal of Nutrition Education, Vol. 18, No. 5, 1986, pp. 215-220. doi:10.1016/S0022-3182(86)80048-6

[2] M. Rossiter, T. Glanville, J. Taylor and I Blum, "School Food Practices of Prospective Teachers," Journal of School Health, Vol. 77, No. 10, 2007, pp. 694-700. doi:10.1111/j.1746-1561.2007.00253.X

[3] M. Y. Kubik, L. A. Lytle, P. J. Hannan, M. Story and C. L. Perry, "Food-Related Beliefs, Eating Behavior, and Classroom Food Practices of Middle School Teachers," Journal of School Health, Vol. 72, No. 8, 2002, pp. 339-345. doi:10.1111/j.1746-1561.2002.tb07921.x

[4] T. A. Elhadad, A. A. Al-Amoudi and A. S. Alzahrani, "Epidemiology, Clinical and Complications Profile of Diabetes in Saudi Arabia: A Review," Annals of Saudi Medicine, Vol. 4, No. 4, 2007, pp. 241-250. doi:10.4103/0256-4947.51484

[5] N. M. AlQauhiz, "Obesity among Saudi Female University Students: Dietary Habits and Health Behaviors,” The Journal of the Egyptian Public Health Association, Vol. 85, No. 1, 2010, pp. 45-59.

[6] N. A. Al-Suliman, "The Health and Nutritional Factors of Chronic Medical Diseases among Saudi Females in Jeddah City," Arab Center for Nutrition, Manama-Bahrain, 2008.

[7] M. O. Al-Rukban, "Obesity among Saudi Male Adolescents in Riyadh, Saudi Arabia,” Saudi Medical Journal, Vol. 24, No. 1, 2003, pp. 27-33.

[8] A. O. Musaiger, "Socio-Cultural and Economic Factors Affecting Food Consumption Patterns in the Arab Countries," Perspectives in Public Health, Vol. 113, No. 2, 1993, pp. 68-74.

[9] B. A. Bakhotmah, "The Puzzle of Self-Reported Weight Gain in a Month of Fasting (Ramadan) among a Cohort of Saudi Families in Jeddah, Western Saudi Arabia," Nutrition Journal, Vol. 10, 2011, p. 84. doi:10.1186/1475-2891-10-84

[10] F. M. Midhet, A. A. Al-Mohaimeed and F. K. Sharaf, "Lifestyle Related Risk Factors of Type 2 Diabetes Mellitus in Saudi Arabia,” Saudi Medical Journal, Vol. 31, No. 7, 2010, pp. 768-774.

[11] H. M. Al-Hazzaa, "Prevalence of Physical Inactivity in Saudi Arabia: A Brief Review," East Mediterranean Health Journal, Vol. 10, No. 4-5, 2004, pp. 663-670.

[12] M. S. Shaath, "Consumption of Fast Foods among Females’ Adolescents in Jeddah City,” Arab Center of Nutrition, Manama-Bahrain, 2008.

[13] S. A. Washi and M. B. Ageib, "Poor Diet Quality and Food Habits are Related to Impaired Nutritional Status in 13- to 18-Year-Old Adolescents in Jeddah,” Nutrition Research, Vol. 30, No. 8, 2010, pp. 527-534. doi:10.1016/j.nutres.2010.07.002

[14] A. S. Al-Rethaiaa, A. A. Fahmy and N. M. Al-Shwaiyat, "Obesity and Eating Habits among College Students in Saudi Arabia: A Cross Sectional Study,” Nutrition Journal, Vol. 9, 2010, p. 39. doi:10.1186/1475-2891-9-39
[15] J. C. Lumeng and K. H. Hillman, "Eating in Larger Groups Increases Food Consumption,” Archives of Disease in Childhood, Vol. 92, No. 5, 2007, pp. 384-387. doi:10.1136/adc.2006.103259

[16] I. A. Hakim, M. A. Alsaif, M. Alduwaihy, K. Al-Rubeaan, A. R. Al-Nuaim and O. S. Al-Attas, "Tea Consumption and the Prevalence of Coronary Heart Disease in Saudi Adults: Results from a Saudi National Study," Preventive Medicine, Vol. 36, No. 1, 2003, pp. 64-70. doi:10.1006/pmed.2002.1130

[17] A. S. Awaad, G. A. Soliman, M. R. Al-Outhman, I. F. Al-Shdoukhi, R. S. Al-Nafisah, J. Al-Shamery, R. Al-Samkhan, M Baqer and N. A. Al-Jaber, "The Effect of Four Coffee Types on Normotensive Rats and Normal/ Hypertensive Human Volunteers," Phytotherapy Research, Vol. 25, No. 6, 2011, pp. 803-808. doi:10.1002/ptr.3333

[18] Ali. M. el Shabrawy and F. M. Felimban, "A Study of the Impact of Arabic Coffee Consumption on Serum Cholesterol," The Journal of the Royal Society for the Promotion of Health, Vol. 113, No. 6, 1993, pp. 288-291. doi:10.1177/146642409311300602

[19] M. A. al Kanhal, "Lipid Analysis of Coffea Arabica Linn. Beans and Their Possible Hypercholesterolemic Effects," International Journal of Food Sciences and Nutrition, Vol. 48, No. 2, 1997, pp. 135-139. doi:10.3109/09637489709006973

[20] M. S. Butt and M. T. Sultan, "Coffee and Its Consumption: Benefits and Risks," Critical Reviews in Food Science and Nutrition, Vol. 51, No. 4, 2011, pp. 363-373.

[21] M. A. Al-Farsi and C. Y. Lee, "Nutritional and Functional Properties of Dates: A Review," Critical Reviews in Food Science and Nutrition, Vol. 48, No. 10, 2008, pp. 877-887. doi:10.1080/10408390701724264

[22] P. K. Vayalil, "Date Fruits (Phoenix dactylifera Linn): An Emerging Medicinal Food," Critical Reviews in Food Science and Nutrition, Vol. 52, No. 5, 2012, pp. 249-271. doi:10.1080/10408398.2010.499824

[23] H. M. Habib and W. H. Ibrahim, "Nutritional Quality of 18 Date Fruit Varieties," International Journal of Food Sciences and Nutrition, Vol. 62, No. 5, 2011, pp. 544-551. doi:10.3109/09637486.2011.558073

[24] A. O. Musaiger, "Food Composition Tables for Arab Gulf Countries (Gulfoods)” Arab Center for Nutrition, Manama-Bahrain, 2006.

[25] M. A. al-Kanhal, I. S. al-Mohizea, A. I. al-Othaimeen and M. A. Khan, "Nutritive Value of Various Breads in Saudi Arabia," International Journal of Food Sciences and Nutrition, Vol. 50, No. 5, 1999, pp. 345-349. doi:10.1080/096374899101076

[26] M. A. al-Kanhal, I. S. al-Mohizea, A. I. al-Othaimeen and M. A. Khan, "Nutritional Evaluation of Some LegumeBased Dishes Consumed in Saudi Arabia," International Journal of Food Sciences and Nutrition, Vol. 49, No. 3, 1998, pp. 193-197. doi:10.3109/09637489809086411

[27] K. van der Horst, T. A Brunner and M. Siegrist, "Ready-Meal Consumption: Associations with Weight Status and Cooking Skills,” Public Health Nutrition, Vol. 14, No. 2, 2011, pp. 239-245. 
doi:10.1017/S1368980010002624

[28] M. S. Ardawi, M. H. Qari, A. A. Rouzi, A. A. Maimani and R. M. Raddadi, "Vitamin D Status in Relation to Obesity, Bone Mineral Density, Bone Turnover Markers and Vitamin D Receptor Genotypes in Healthy Saudi Preand Postmenopausal Women," Osteoporosis International, Vol. 22, No. 2, 2011, pp. 463-475. doi:10.1007/s00198-010-1249-7 